\title{
ERRATUM
}

\section{Stress transfer between thirteen successive dyke intrusions in Ethiopia}

Ian J. Hamling, Tim J. Wright, Eric Calais, Laura Bennati and Elias Lewi

Nature Geoscience 3, 713-717 (2010); published online: 26 September 2010; corrected after print: 1 October 2010.

In the version of this Letter originally published, the positions of several of the outlines of dyke openings in Figure 2 were incorrect and should have been as shown here. These errors have now been corrected in the HTML and PDF versions of the text.
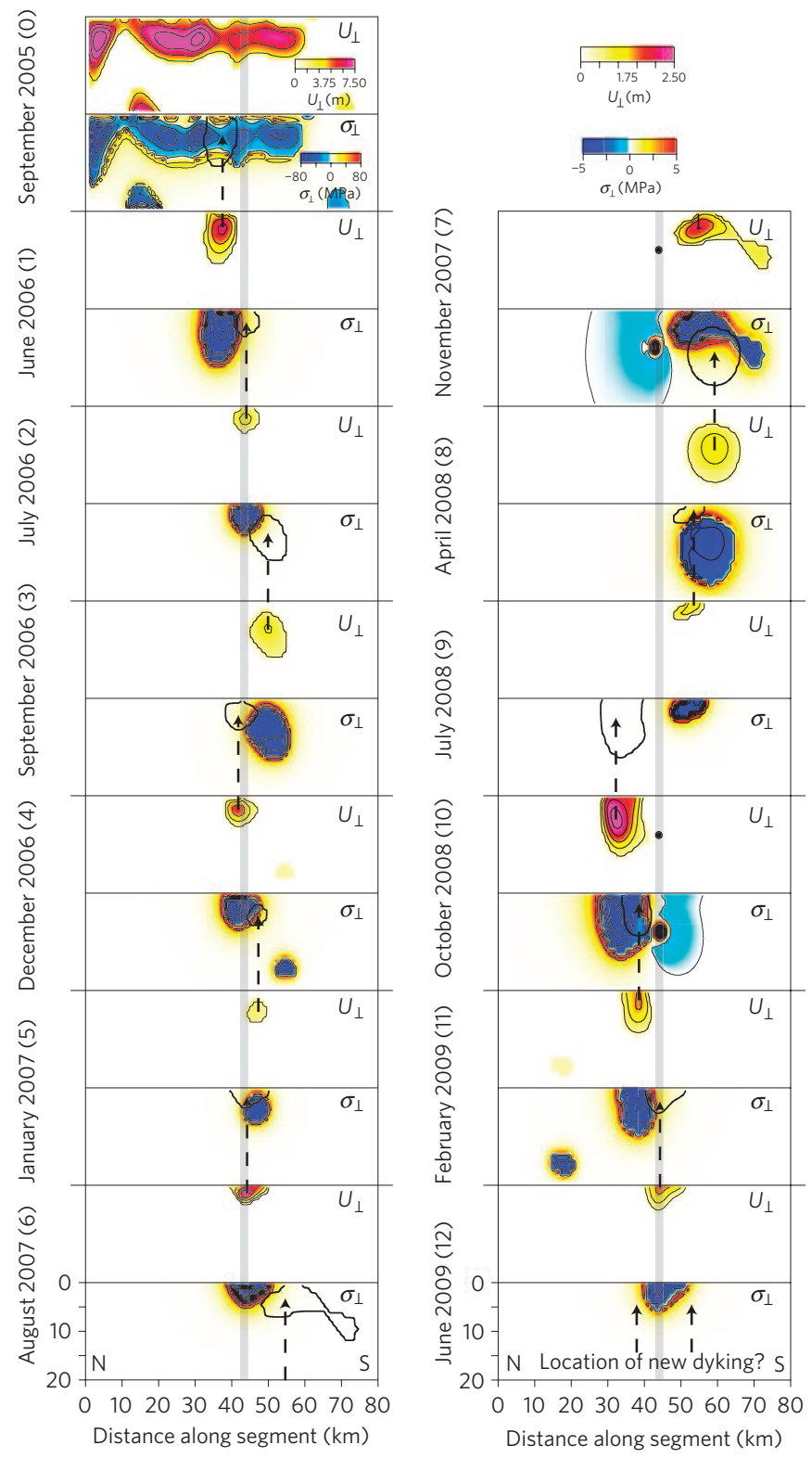